\title{
Surgical excision: an effective initial therapeutic option in the management of giant macrocystic lymphatic malformations in children
}

\author{
Moaied A. Hassan ${ }^{1 *}$ (D), Hasan K. Gatea ${ }^{2}$ and Thura K. Ja'afar ${ }^{1}$
}

\begin{abstract}
Background: Lymphatic malformations are rare benign cystic tumors that result from localized disordered embryologic development of the lymphatic system and can develop anywhere in the body, predominantly in the head and neck. These lesions are classified according to the diameter of the largest cystic cavity within the lesion into microcystic and macrocystic types. Historically, surgical excision has been considered the mainstay of treatment and still remains the first therapeutic option of choice for many surgeons particularly for giant macrocystic lesions. Several alternative therapeutic modalities emerged including intralesional sclerotherapy and laser therapy with encouraging results.

The study is designed to assess the effectiveness and safety of surgical excision as an initial therapeutic option in the management of these malformations.

Results: Asymptomatic mass with parental cosmetic and functional concerns was the mode of presentation in six (66.7\%) patients. Seven (77.8\%) patients were presented before the age of 2 years. Six (66.7\%) of the patients had their lesions in the neck. Complete surgical excision was achieved in eight (88.9\%) patients without any evident significant injury to vital neurovascular structures. None of the patients had any difficulties with breathing, swallowing, or phonation and cosmetic results were satisfactory in the majority (88.9\%) of them.

Conclusion: Radical surgical excision of giant macrocystic lymphatic malformations in children is possible in experienced hands. It is an effective and safe initial therapeutic option and gives satisfactory esthetic and functional results.
\end{abstract}

Keywords: Lymphatic, Malformation, Macrocystic, Surgical, Excision

\section{Background}

Lymphatic malformations (LMs) are rare benign cystic tumors that result from localized disordered embryologic development of the lymphatic system. Although the exact etiology is still uncertain, a considerable support exists to the theory that abnormal or absent communications between the central venous sacs and the peripheral lymphatic system result in lymphatic accumulation and cyst formation $[1,2]$. LMs can develop

\footnotetext{
* Correspondence: moaied70@yahoo.com

${ }^{1}$ Pediatric Surgery Department and Training Center, Basrah Children's

Specialty Hospital, Basrah, Iraq

Full list of author information is available at the end of the article
}

anywhere in the body, predominantly in the head and neck (75\%) followed by the axilla and mediastinum [3]. Fifty percent of these lesions are detected at birth, and $90 \%$ can be diagnosed before the age of 2 years $[3,4]$. The incidence of lymphatic malformations is estimated to be 1:6000-1:16000 live births [3].

LMs are classified according to the diameter of the largest cystic cavity within the lesion into the macrocystic type, having cysts greater than $2 \mathrm{~cm}$ with clear boundaries and the microcystic type with cysts lesser than $2 \mathrm{~cm}$ and ill-defined boundaries. The two types can coexist in a mixed variety $[4,5]$. The macrocystic type (previously known as cystic hygroma) develops most frequently in the 
neck, whereas the microcystic type (previously known as lymphangioma) develops most frequently in the oral cavity and cheek [5].

Giant macrocystic lymphatic malformations in children usually present as asymptomatic masses with parental esthetic concern as the major consideration. Other ways of presentation are related to the effects or complications of these lesions including respiratory distress, feeding difficulties, and sudden increase in size following infection and hemorrhage [6].

Although benign, LMs rarely regress. Spontaneous regression has been reported in only $1.6-16 \%$ of the cases and with adequate follow-up, recurrence is a usual phenomenon after regression [4].

The management of LMs in children remains challenging especially for those involving the cervicofacial region because of their close relation to adjacent vital structures and their poor demarcation. Historically, surgical excision has been considered the mainstay of treatment and still remains the first therapeutic option of choice for many surgeons particularly for giant macrocystic lesions. Over the past several decades, several alternative therapeutic modalities emerged including intralesional sclerotherapy and laser therapy with encouraging results $[3,4]$. The aim of this study is to assess the effectiveness and safety of surgical excision as an initial therapeutic modality in the treatment of giant macrocystic lymphatic malformations in children.

\section{Methods}

A retrospective study of nine patients with giant macrocystic lymphatic malformations were managed in the Pediatric Surgery Department at Basrah Children's Specialty Hospital during the period from July 2012 to July 2018. Surgical excision was the initial and only therapeutic modality in all patients. Intralesional sclerotherapy or any other adjuvant therapy was not attempted in this study. Recorded clinical data included sex, age at presentation, mode of presentation, lesion site and laterality, lesion size, and intraoperative and postoperative complications. The diagnosis was confirmed by clinical history, physical examination, ultrasonography, and magnetic resonance imaging. Complete surgical excision was the primary goal in all patients with special care to avoid injury to vital neurovascular structures. All patients underwent follow-up for a 1 year postoperatively regarding the functional and cosmetic results.

\section{Results}

Of the nine patients enrolled in this study, five (55.6\%) were males and four (44.4\%) were females. Seven (77.8\%) patients were presented before the age of 2 years. One patient was presented at 3 years of age and one patient at 12 years of age. Six (66.7\%) patients had their

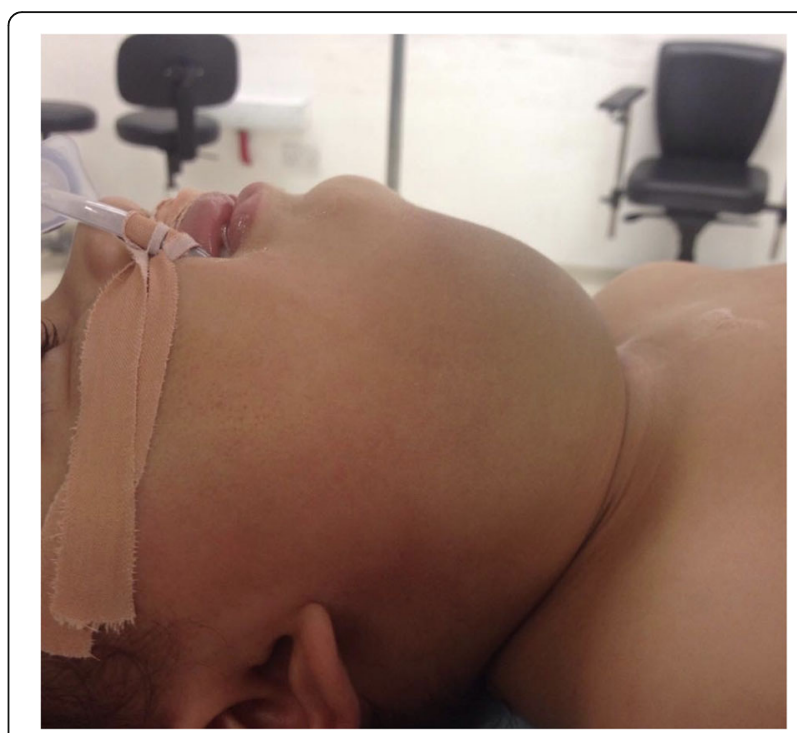

Fig. 1 One-year-old child with lymphatic malformation of the right neck

lesions in the neck (Fig. 1), of whom two were with bilateral involvement (Fig. 2) and one with bilateral involvement plus extension into the base of the tongue. One patient had the lesion in the left chest wall, one in the suprasternal region, and one in the left axilla. The lesion size ranged from $6 \mathrm{~cm} \times 4 \mathrm{~cm}$ to $12 \mathrm{~cm} \times 10 \mathrm{~cm}$ (average, $9.4 \mathrm{~cm} \times 7.2 \mathrm{~cm}$ ). Sex, age at presentation, and lesion site and size are summarized in Table 1.

Asymptomatic mass with parental cosmetic and functional concerns was the mode of presentation in six (66.7\%) patients. Two (22.2\%) patients suffered a sudden

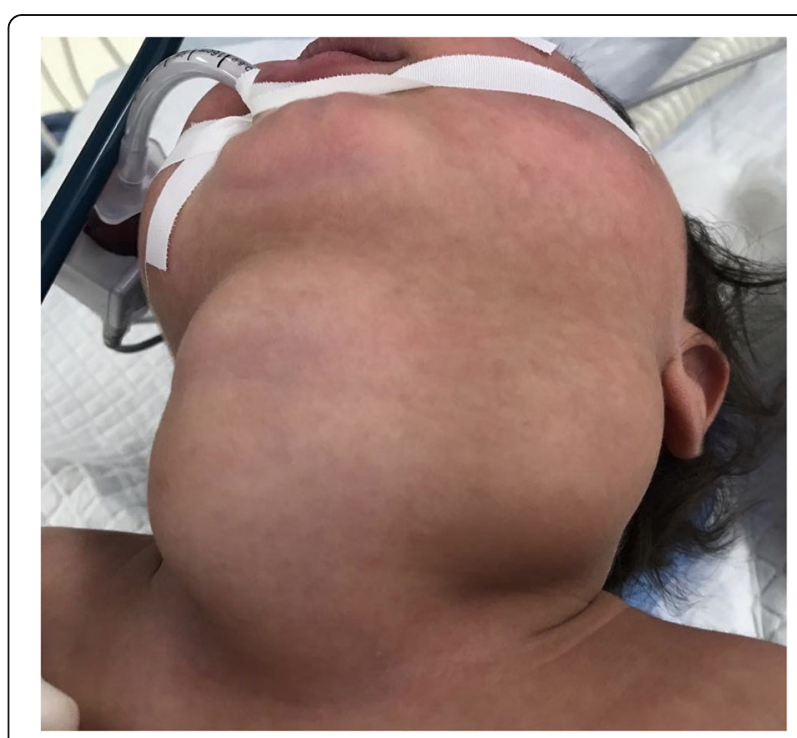

Fig. 2 Eleven-month-old male with bilateral neck involvement 
Table 1 Distribution of sex, age at presentation, and lesion site and size

\begin{tabular}{|c|c|c|c|c|}
\hline Sex & Age at presentation & Lesion site & Lesion size & $\begin{array}{l}\text { Size of the largest cyst } \\
\text { within the lesion }\end{array}$ \\
\hline Female & 9 months & Suprasternal & $6 \times 4 \mathrm{~cm}$ & Unilocular cyst $6 \times 4 \mathrm{~cm}$ \\
\hline Male & 11 months & Neck (bilateral) & $10 \times 8 \mathrm{~cm}$ & $6 \times 5 \mathrm{~cm}$ \\
\hline Male & 1 year & Neck (right side) & $10 \times 7 \mathrm{~cm}$ & $8 \times 4 \mathrm{~cm}$ \\
\hline Female & 1 year & Neck (right side) & $8 \times 6 \mathrm{~cm}$ & $6 \times 3 \mathrm{~cm}$ \\
\hline Male & 1 year & Neck (bilateral) & $10 \times 8 \mathrm{~cm}$ & $8 \times 6 \mathrm{~cm}$ \\
\hline Female & 15 months & Neck (bilateral) & $12 \times 9 \mathrm{~cm}$ & $8 \times 5 \mathrm{~cm}$ \\
\hline Female & 18 months & Left axilla & $8 \times 6 \mathrm{~cm}$ & Unilocular cyst $8 \times 6 \mathrm{~cm}$ \\
\hline Male & 3 years & Left chest wall & $12 \times 10 \mathrm{~cm}$ & $7 \times 5 \mathrm{~cm}$ \\
\hline Male & 12 years & Neck (left) & $9 \times 7 \mathrm{~cm}$ & Unilocular cyst $9 \times 7 \mathrm{~cm}$ \\
\hline
\end{tabular}

increase in the size of their lesions due to infection and both were admitted and given parenteral antibiotic therapy prior to surgical excision. One (11.1\%) patient was presented with a huge bilateral cervical lesion with extension into the base of the tongue causing respiratory distress and feeding difficulties that necessitated admission to the intensive care unit for close monitoring. At surgery, it was not possible to intubate the patient, and aspiration of the cyst was performed to reduce the bulk of the lesion before placing the endotracheal tube.

Complete surgical excision was achieved in eight $(88.9 \%)$ patients without any evident significant injury to vital neurovascular structures (Fig. $3 a-c)$. Residual lesion was left in only one (11.1\%) patient with giant lymphatic malformation involving both sides of the neck with extension into the base of the tongue. The lingual base lesion was left untouched for further possible therapeutic alternatives to avoid unnecessary lingual damage. Wound healing was excellent in eight (88.9\%) patients. One patient with lymphatic malformation involving the chest wall suffered postoperative wound infection and prolonged tube drainage. All of the patients were followed up for 1 year postoperatively. None of them had any difficulties with breathing, swallowing, or phonation. Cosmetic results were satisfactory in eight (88.9\%) patients. One (11.1) patient suffered an esthetic problem regarding the symmetry of the neck contour following the removal of a big lymphatic malformation involving both sides of the neck.

\section{Discussion}

Lymphatic malformations are rare benign tumors that stem from a malformation of the lymphatic vessels in the soft tissues and account for $5-6 \%$ of all benign soft tissue tumors in children $[1,5,7]$. The majority (75\%) of these lesions develop in the cervicofacial region and the diagnosis can be done before the age of 2 years in $90 \%$ of the cases [3, 4]. No significant sexual or racial differences have been reported regarding

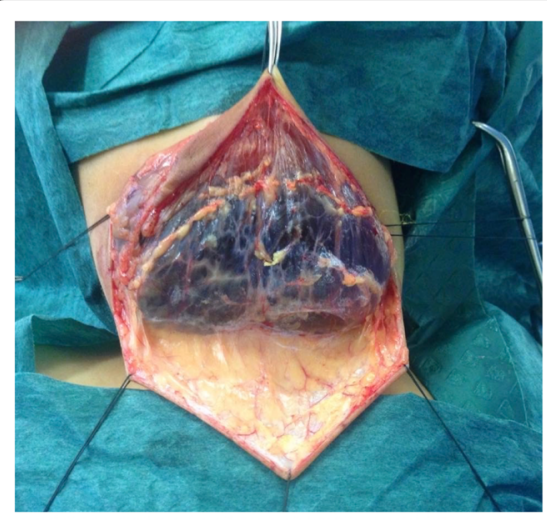

A

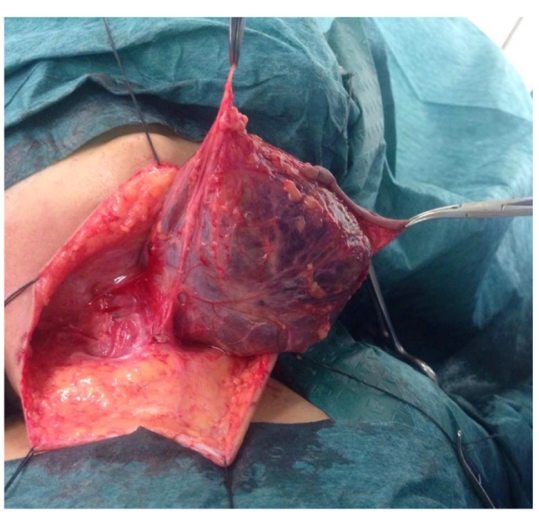

B

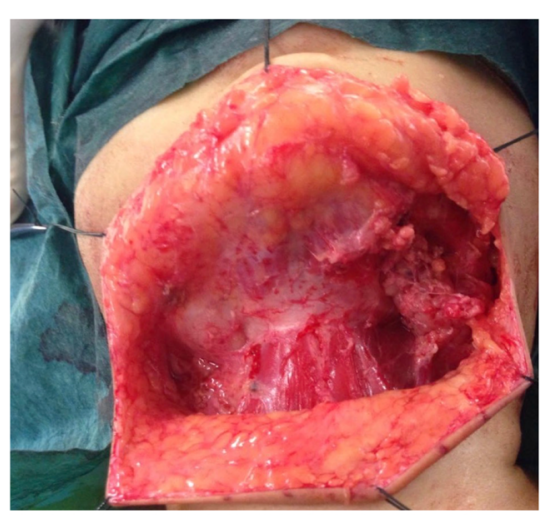

C

Fig. 3 a Generous skin flaps to facilitate dissection of the hygroma. $\mathbf{b}$ Complete release of the mass from the right side of the neck. c Clear tumor bed 


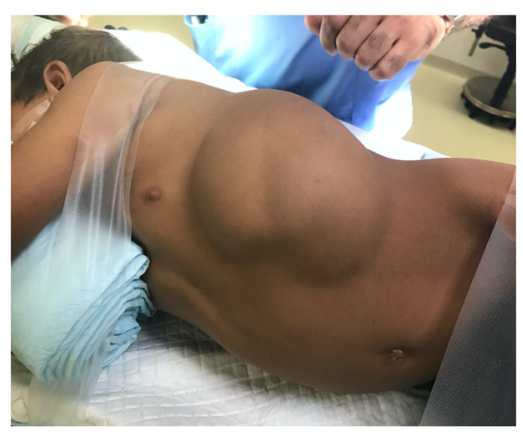

A

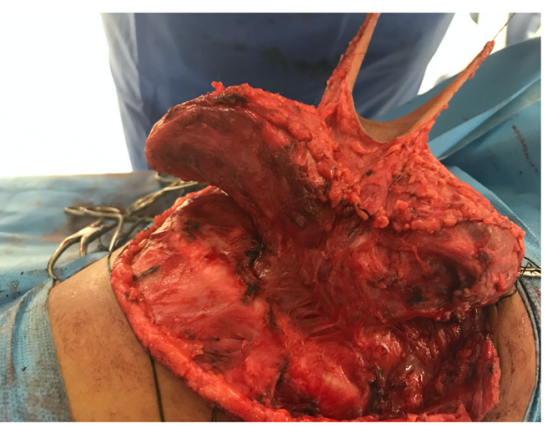

B

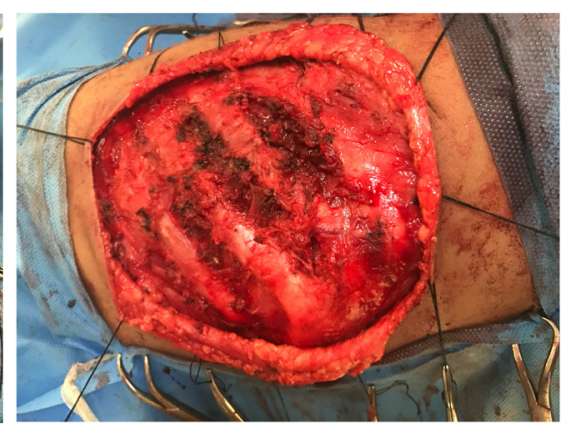

C

Fig. 4 a 3-year-old child with lymphatic malformation of the left chest wall. b Dissecting the tumor from the surrounding tissues. c Complete resection with the intercostal spaces exposed

the incidence of LMs [7]. In this study, $66.7 \%$ of the patients had their lesions in the neck, $77.8 \%$ of the patients were presented before the age of 2 years, and the male to female ratio was 1:0.8.

Macrocystic lymphatic malformations are defined as those lesions with cysts greater than $2 \mathrm{~cm}$ in diameter and having clear boundaries $[4,5]$. Asymptomatic mass with parental esthetic concern is the usual presentation of macrocystic lymphatic malformations in infants and children. Even when large, these lesions may not cause symptoms as they grow within an overlying elastic skin and subcutaneous tissue especially in the cervicofacial region where these lesions predominate [7]. Painless mass was the mode of presentation in the majority (66.7\%) of patients in this study. Similar findings were reported in previous relevant series $[7,8]$.

Lymphatic malformations are liable to infection because the abnormal lymphatic vessels have limited ability to clear foreign materials, besides, the high proteinaceous fluid and blood content of the cysts in favor of bacterial overgrowth [9]. Two (22.2\%) patients in this study suffered infection of their lesions and both were given injectable antibiotic therapy to resolve the problem preoperatively. Infection rates are comparable to those reported in other studies [8].

Respiratory distress with feeding difficulties are serious complications of LMs that result from a sudden increase in the size of the lesion following infection or intralesional bleeding or secondary to compression of the mass on the upper airway. In our study, these serious complications were reported in one (11.1\%) patient with a giant lymphatic malformation involving both sides of the neck with extension into the lingual base. Similar results were observed in similar previous studies [8].

Historically, surgical excision has been the initial therapeutic option for LMs, and since the first

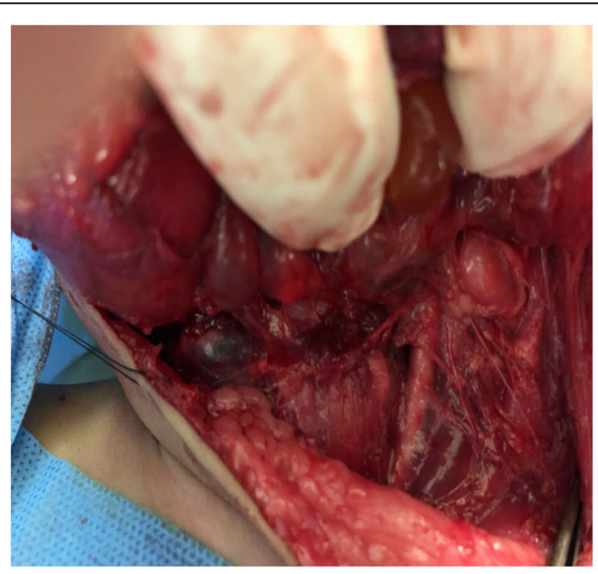

A

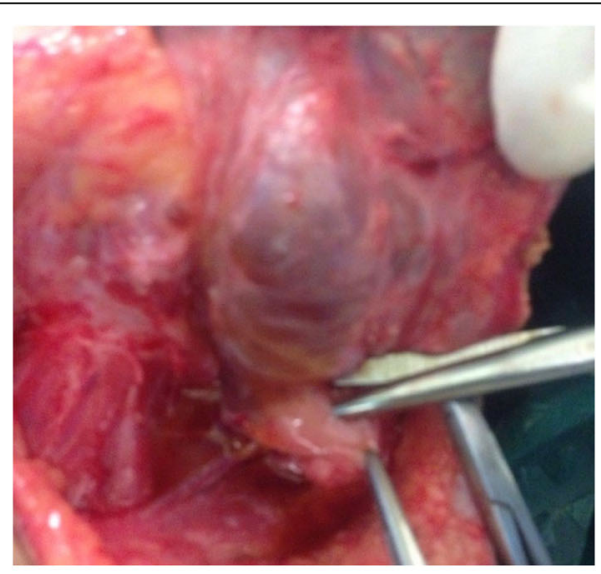

B

Fig. 5 a Separating the mass from the carotid sheath. $\mathbf{b}$ Separating the mass from the salivary gland 


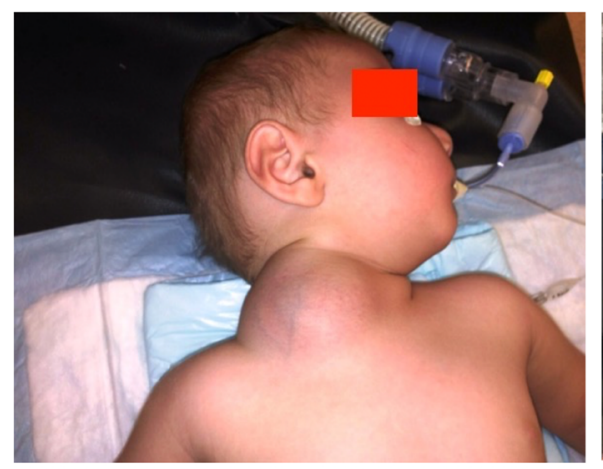

A

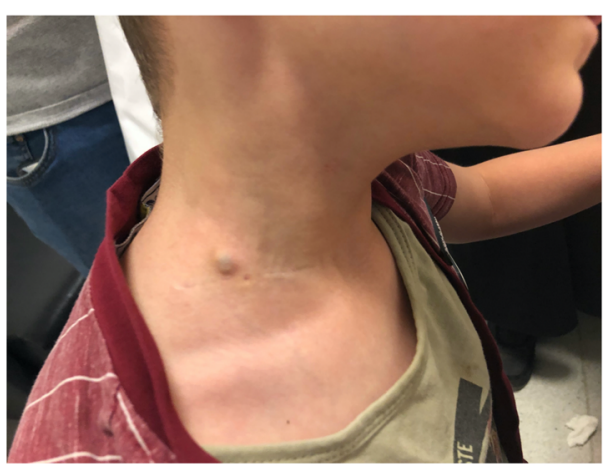

B

Fig. 6 a 1-year-old child with cervical lymphatic malformation. b The same patient after 2 years

description of the macrocystic variety, several therapeutic modalities including intralesional sclerotherapy and laser therapy have emerged; however, surgery remains the initial therapeutic option of choice for many surgeons and has proven effective [3, 8]. Surgical resection of giant macrosystic LMs is challenging. These lesions tend to insinuate major blood vessels, nerves, and muscles, and all surgeons attempting radical surgical excision should be aware of the anatomic details to avoid unnecessary damage to vital structures. Patients with cervicofacial lesions in particular are at risk of airway obstruction, functional damage, and recurrent or persistent lesions [8].

In this study, radical surgical excision was achieved in the majority (88.9\%) of patients (Fig. $4 a-c$ ). No significant neurovascular damage has been reported in any of the patients operated upon (Fig. 5a, b). All of the patients regained full immediate postoperative recovery following uneventful extubation. Residual lesion was recorded in only one patient with a giant lesion involving both sides of the neck with sublingual extension. Ma et al. and Chen et al. reported complete surgical resection in $82.4 \%$ and $89.4 \%$ of their case series respectively $[7,8]$.

No major postoperative complications regarding problems with breathing, swallowing, or phonation were recorded in this study. Cosmetic results were satisfactory in the majority (88.9\%) of patients (Figs. 6 and 7) and no recurrence was reported after 1 year of follow-up. Similar results were reported in previous other studies [8].

Over the past several decades, several alternative therapeutic modalities emerged including the use of intralesional sclerotherapy. In 2014, Balakrishnan et al. [10] were the first to do a head-head comparison between primary surgery and primary sclerotherapy in the treatment of head and neck LMs and found that both modalities were equally effective in a multisite comparison. In 2007, Okazaki et al. [11] reported serious complications of treating LMs with OK-432 and surgery. They found that sclerotherapy may cause fever, infection, upper respiratory tract obstruction, or anaphylactic shock and suggested that sclerotherapy with OK-432 was not as effective as previously reported.

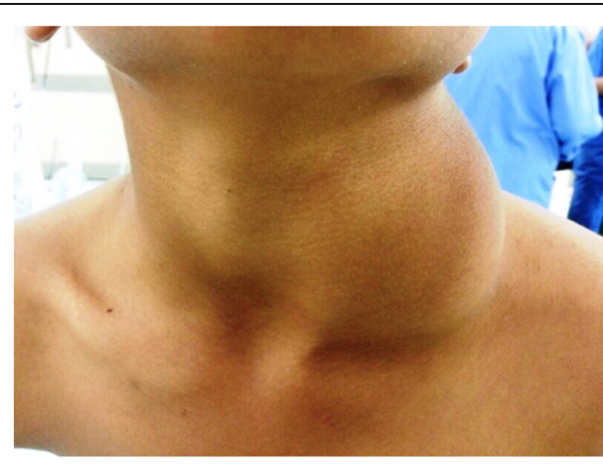

A

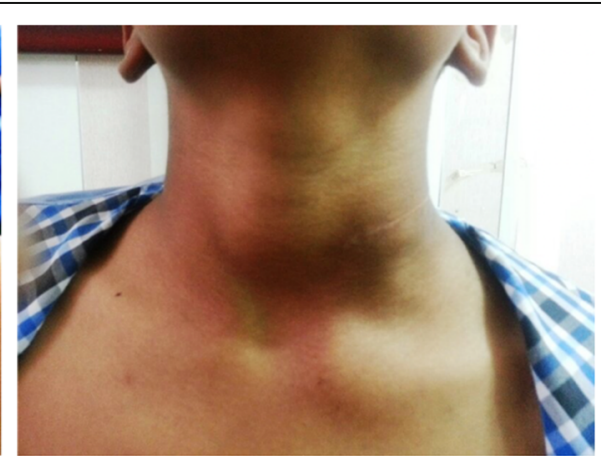

B

Fig. 7 a 12-year-old child with cervical lymphatic malformation. b The same patient after 1 year 


\section{Conclusions}

Radical surgical excision of giant macrocystic lymphatic malformations in children is possible in experienced hands. It is an effective and safe initial therapeutic option and gives satisfactory esthetic and functional results.

\section{Abbreviations}

LMs: Lymphatic malformations

\section{Acknowledgements}

Not applicable

\section{Authors' contributions}

$\mathrm{MH}$ played a major role in writing the manuscript and reviewing the literature, HG contributed significantly in revising the article and shared reviewing the literature and TJ collected and analyzed the data and shared reviewing the literature. All authors have read and approved the manuscript.

\section{Funding}

The authors declare that they have no funding

\section{Availability of data and materials}

Further details and data are available on a reasonable request provided that patients' confidentiality will not be publicly disclosed.

\section{Ethics approval and consent to participate}

The study was approved by the Department of Surgery Review Board/ Pediatric Surgery Department/Basrah Children's Specialty Hospital, as we do not have formal institutional review board or ethics committee. Reference number is not applicable. Informed written consent was obtained from the care giver.

\section{Consent for publication}

An informed consent for publication of data and images was taken from parents/care givers.

\section{Competing interests}

The authors declare that they have no competing interests.

\section{Author details}

${ }^{1}$ Pediatric Surgery Department and Training Center, Basrah Children's Specialty Hospital, Basrah, Iraq. ${ }^{2}$ Iraqi Board for Medical Specializations, Baghdad, Iraq.

Received: 11 October 2019 Accepted: 9 December 2019

Published online: 03 January 2020

\section{References}

1. Oosthuizen JC, Burns P, Russell JD. Lymphatic malformations: a proposed management algorithm. Int J Pediatr Otorhinolaryngol. 2010;74:398-403.

2. Boardman SJ, Cochrane LA, Roebuck D, Elliott MJ, Hartley BE. Multimodality treatment of pediatric lymphatic malformations of the head and neck using surgery and sclerotherapy. Arch Otolaryngol Head Neck Surg. 2010;136(3):270-6.

3. Churchill P, Otal D, Pemberton J, Ali A, Flageole H, Walton JM. Sclerotherapy for lymphatic malformations in children: a scoping review. J Pediatr Surg. 2011;46:912-22.

4. Zhou Q, Zheng JW, Mai HM, Luo QF, Fan XD, Li Xin S, Wang YA, Qin ZP. Treatment guidelines of lymphatic malformations of the head and neck. Oral Oncology. 2011:47:1105-9.

5. Cho BC, Kim JB, Lee JW, Choi KY, Yang JD, Lee SJ, Kim YS, Lee JM, Huh $S$, Chung HY. Cervicofacial lymphatic malformations: a retrospective review of 40 cases. Arch Plast Surg. 2016:43:10-8.

6. Mirza B, ljaz L, Saleem M, Sharif M, Sheikh A. Cystic hygroma: an overview. J Cutan Aesthet Surg. 2010:3:139-44.

7. Ma J, Biao R, Lou F, Lin K, Yq G, Ml W, YI Y, Ts Z. Diagnosis and surgical treatment of cervical macrocystic lymphatic malformations in infants. Experimental and Therapeutic Medicine. 2017;14:1293-8.
8. Chen WL, Zhang B, Wang JG, Ye HS, Zhang DM, Huang ZQ. Surgical excision of cervicofacial giant macrocystic lymphatic malformations in infants and children. Int J Pediatr Otorhinolar- yngol. 2009;73:833-7.

9. Greene AK, Perlyn CA, Alomari Al. Management of lymphatic malformations. Clin Plast Surg. 2011;38(1):75-82.

10. Balakrishnan K, Menezes MD, Chen BS, Magit AE, Perkins JA. Primary surgery vs primary sclerotherapy for head and neck lymphaticmal formations. JAMA Otolaryngol Head Neck Surg. 2014;140:41-5.

11. Okazaki T, Iwatani S, Yanai T, Kobayashi H, Kato Y, Maru-sasa T, Lane GJ, Yamataka A. Treatment of lymphangioma in children: our experience of 128 cases. J Pediatr Surg. 2007:42:386-9.

\section{Publisher's Note}

Springer Nature remains neutral with regard to jurisdictional claims in published maps and institutional affiliations.

\section{Submit your manuscript to a SpringerOpen ${ }^{\circ}$ journal and benefit from:}

- Convenient online submission

- Rigorous peer review

- Open access: articles freely available online

- High visibility within the field

- Retaining the copyright to your article

Submit your next manuscript at $\boldsymbol{\nabla}$ springeropen.com 